\title{
FIELD PERFORMANCE OF ALL-FIBER PULSED COHERENT DOPPLER LIDAR
}

\author{
Heng Liu ${ }^{1,2}$, Xiaopeng Zhu ${ }^{* 1}$, Chunhui Fan ${ }^{3}$, Decang Bi ${ }^{1}$, Jiqiao Liu ${ }^{* 1}$, Xin Zhang ${ }^{1}$, Xiaolei Zhu ${ }^{1}$, \\ Weibiao Chen ${ }^{1}$ \\ ${ }^{1}$ Key Laboratory of Space Laser Communication and Detection Technology, Shanghai Institute of Optics \\ and Fine Mechanics, Chinese Academy of Science, Shanghai 201800, China \\ ${ }^{2}$ Center of Materials Science and Optoelectronics Engineering, University of Chinese Academy of \\ Sciences, Beijing 100049, China \\ ${ }^{3}$ College of Meteorology and Oceanography, National university of defense technology, Nanjing 211101, \\ China \\ *Email:xp_zhu@siom.ac.cn,liujiqiao@siom.ac.cn
}

\begin{abstract}
Coherent Doppler lidar (CDL) has been a powerful instrument to measure atmospheric wind velocity. In this work, an $1.5 \mu \mathrm{m}$ all-fiber pulsed CDL has been developed and deployed to measure wind profiles in campaign experiment in 2018. The CDL has 0.1-5 km detection range with range resolution of $30 \mathrm{~m}$, temporal resolution of $16 \mathrm{~s}$ at Velocity-Azimuth-Display (VAD) mode. Field experiments were implemented and the wind vector profiles were retrieved. As compared with sounding balloon, the discrepancy of wind speed and direction are nearly $0.7 \mathrm{~m} / \mathrm{s}$ and 5 degrees, respectively. It shows that the CDL is a powerful tool for wind speeds measurement in lower atmospheric troposphere.
\end{abstract}

\section{INTRODUCTION}

$1.5 \mu \mathrm{m}$ all-fiber pulsed CDL has attracted much attentions due to its eye safety, compact size, flexible deployment and mature fiber components technology from telecommunication industry.[1] Mitsubishi Electric Corporation has developed an airborne $1.5 \mu \mathrm{m}$ pulsed CDL which can detect as far as $9.3 \mathrm{~km}$ with changeable range resolution of 30, 75 and $150 \mathrm{~m}$.[2] Leosphere displays a long range lidar (Windcube 200S) which can measure $3 \mathrm{D}$ wind profiles up to $7 \mathrm{~km}$ with $70 \mathrm{~m}$ range resolution, $0.5 \mathrm{~m} / \mathrm{s}$ velocity resolution and $1 \mathrm{~s}$ time resolution.[3] Prasad et al. have presented a 1.54 $\mu \mathrm{m}$ all-fiber pulsed CDL which can measure wind velocity greater than $120 \mathrm{~m} / \mathrm{s}$ over ranges greater than $10 \mathrm{~km}$ and its range resolution is less than 15 m.[4] $\mathrm{Wu}$ et al. have designed a $1.5 \mu \mathrm{m}$ pulsed $\mathrm{CDL}$ with high updating rate of $4 \mathrm{~Hz}$ and variable physical spatial resolution from 15-60 m.[5] In this study, an all-fiber single mode laser with pulse energy of $300 \mu \mathrm{J}$, pulse width of $400 \mathrm{~ns}$ and repetition rate of $10 \mathrm{kHz}$ is used to measure wind velocity in range of $0.1-5 \mathrm{~km}$. The CDL shows good stability and reliability in field campaign.

\section{METHODOLOGY}

\subsection{The lidar system}

The pulsed CDL for wind velocity measurement is operated by transmitting high energy narrow bandwidth laser beam into the atmosphere, which can acquire LOS velocity by analyzing the Doppler shift between objective backscattered signal and local oscillator. The key technologies are composed by: High-power single-frequency pulsed laser technology, optical antenna system, high sensitivity heterodyne detection technology, signal acquisition and real-time processing technology, as is shown in Fig. 1.

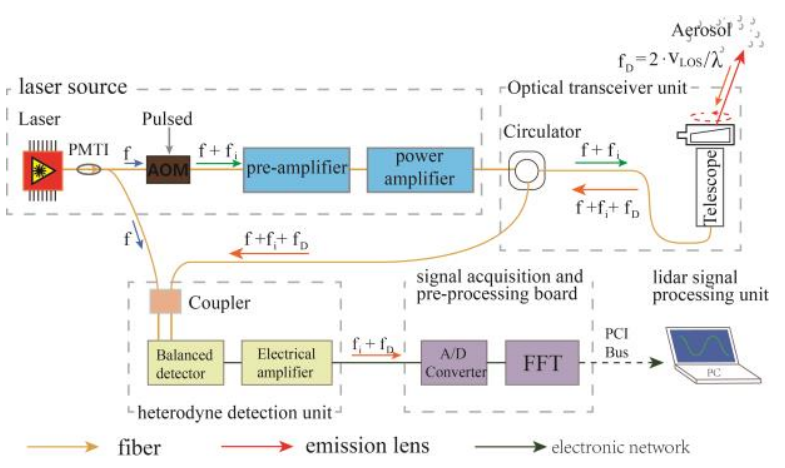

Figure 1. System diagram of the ground-based lidar.

The main system parameters are shown in Tab. 1 .

Table 1. Main parameters of the pulsed coherent Doppler lidar system. 


\begin{tabular}{llc}
\hline Component & Qualification & Specification \\
\hline Transmitter & Operating wavelength & $1540 \mathrm{~nm}$ \\
& Pulse energy & $300 \mu \mathrm{J}$ \\
& Pulse repetition rate & $10 \mathrm{kHz}$ \\
& Pulse width & $400 \mathrm{~ns}$ \\
\hline Transceiver & telescope diameter & $100 \mathrm{~mm}$ \\
& scan mode & Conical \\
& zenith angle & $20^{\circ}$ \\
& azimuth & 8 \\
& scanning time & $16 \mathrm{~s}$ \\
\hline Data- & sampling frequency & $1 \mathrm{GHz}$ \\
Acquisition & sampling length & $40 \mu \mathrm{s}$ \\
& range resolution & $30 \mathrm{~m}$ \\
\hline
\end{tabular}

\subsection{Comparison of CDL and sounding balloon}

Sounding balloon detects wind speed through calculating its azimuth angle and elevation angle in unit time. The dataset from sounding balloon record $30 \mathrm{~s}$ average wind speed, updating time of $1 \mathrm{~s}$, vertical range resolution of near $5 \mathrm{~m}$. Horizontal space range between sounding balloon and CDL is near $50 \mathrm{~m}$. The comparison scheme is given based on the quality of sounding balloon and CDL.

Table 1: comparison scheme between sounding balloon and CDL.

\begin{tabular}{|l|c|c|c|}
\hline & $\begin{array}{l}\text { Temporal } \\
\text { resolution }\end{array}$ & $\begin{array}{l}\text { Dataset } \\
\text { updating } \\
\text { time }\end{array}$ & $\begin{array}{l}\text { Range } \\
\text { resolution }\end{array}$ \\
\hline $\begin{array}{l}\text { Sounding } \\
\text { balloon }\end{array}$ & $30 \mathrm{~s}$ & $1 \mathrm{~s}$ & $5 \mathrm{~m}$ \\
\hline CDL & $16 \mathrm{~s}$ & $2 \mathrm{~s}$ & $30 \mathrm{~m}$ \\
\hline Comparison & $30 \mathrm{~s}$ & $\sim 1 \mathrm{~s}$ & $30 \mathrm{~m}$ \\
\hline
\end{tabular}

\section{RESULTS}

\subsection{Continuous measurement of CDL}

On Aug. 10th ,2018, the comparison experiments are implemented in Jingbian city, Shanxi province, China, with local altitude of $1332 \mathrm{~m}$. The ground- based CDL obtained a continuous 3D wind field dataset, as shown in Fig. 2.

There is a frontal surface (the interface between cold and warm wind) in range of 1500 to $2000 \mathrm{~m}$. The continuous wind-profiles measurement displays the detailed characteristic wind zone which is meaningful in wind field monitoring.

Another point is that CDL signal shows the change of cloud base height from 22:00 to 23:00. The cloud base is higher than $5000 \mathrm{~m}$ (Altitude value) in that time. This feature captured by CDL can express its operational capacity below the boundary layer.
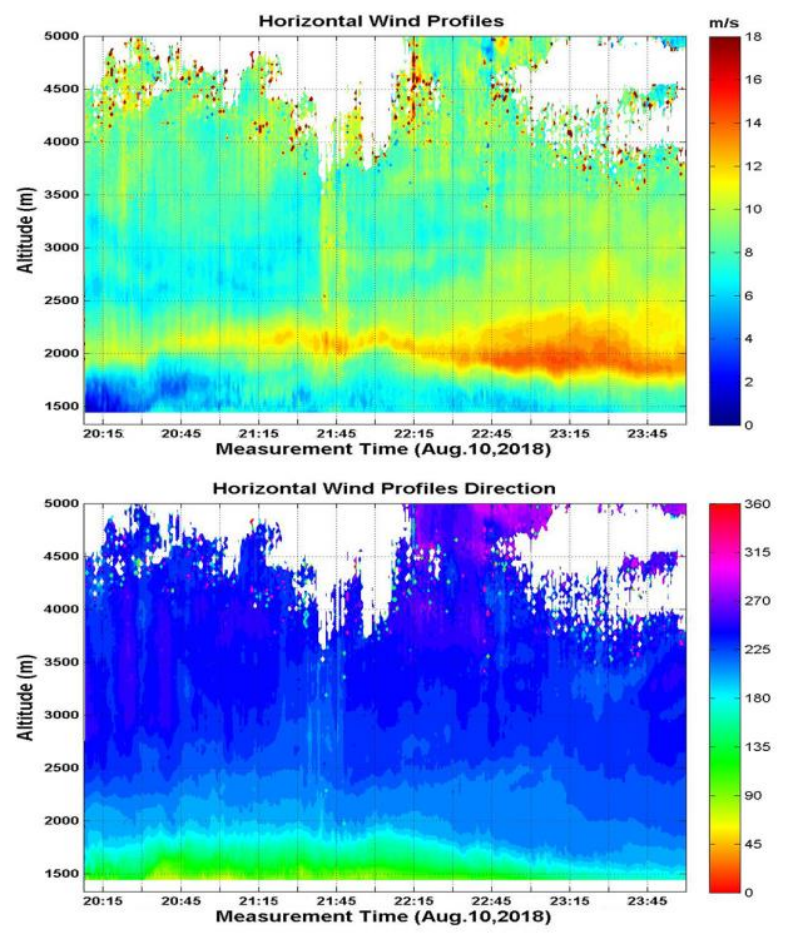

Figure 2: Horizontal wind profiles measured by CDL on Aug. 10th, 2018.

\subsection{CDL and sounding balloon measurement}

Measurements experiment of CDL and sounding balloon almost on the same time is implemented in August, 2018. Relative position of the two instruments are marked in Fig. 3. The horizontal space distance between CDL and sounding balloon on the ground is less than $50 \mathrm{~m}$. 


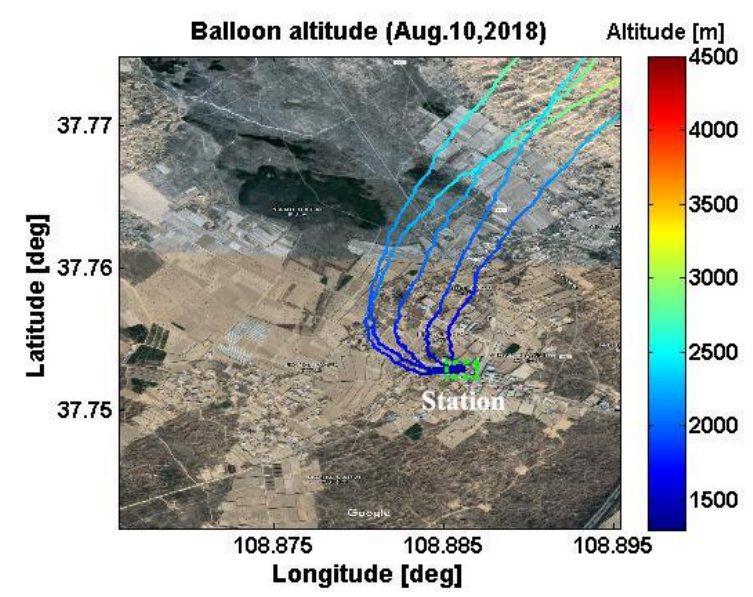

Figure 3: Relative position of sounding baloon and CDL. The color lines show tracks of the altitude of sounding baloon.

Samples of the comparison of wind speed are shown on the left side below. Wind speed of two instruments shows similar tendency. There are differences in $30 \mathrm{~s}$ average wind speed in range of $1 \sim 2 \mathrm{~m} / \mathrm{s}$, this discrepancy might become decrease after longer temporal average. On the right side, comparison of wind direction shows accordance in most situations.
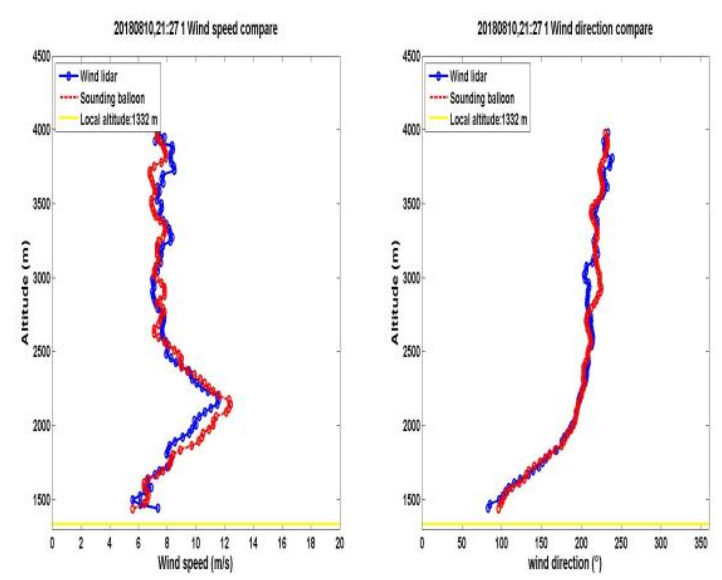

Figure 4: Comparison of wind speed and wind direction measured by CDL and sounding balloon.

Numerous analysis of the differences is shown on Fig. 5. Take the dataset on Aug. 10th, 2018 as an example, the discrepancy of wind speed and wind direction is less than $1 \mathrm{~m} / \mathrm{s}$ and 5 degrees between $\mathrm{CDL}$ and sounding balloon, respectively. It shows good agreement of wind detection in two different methods, which prove the accuracy of CDL.
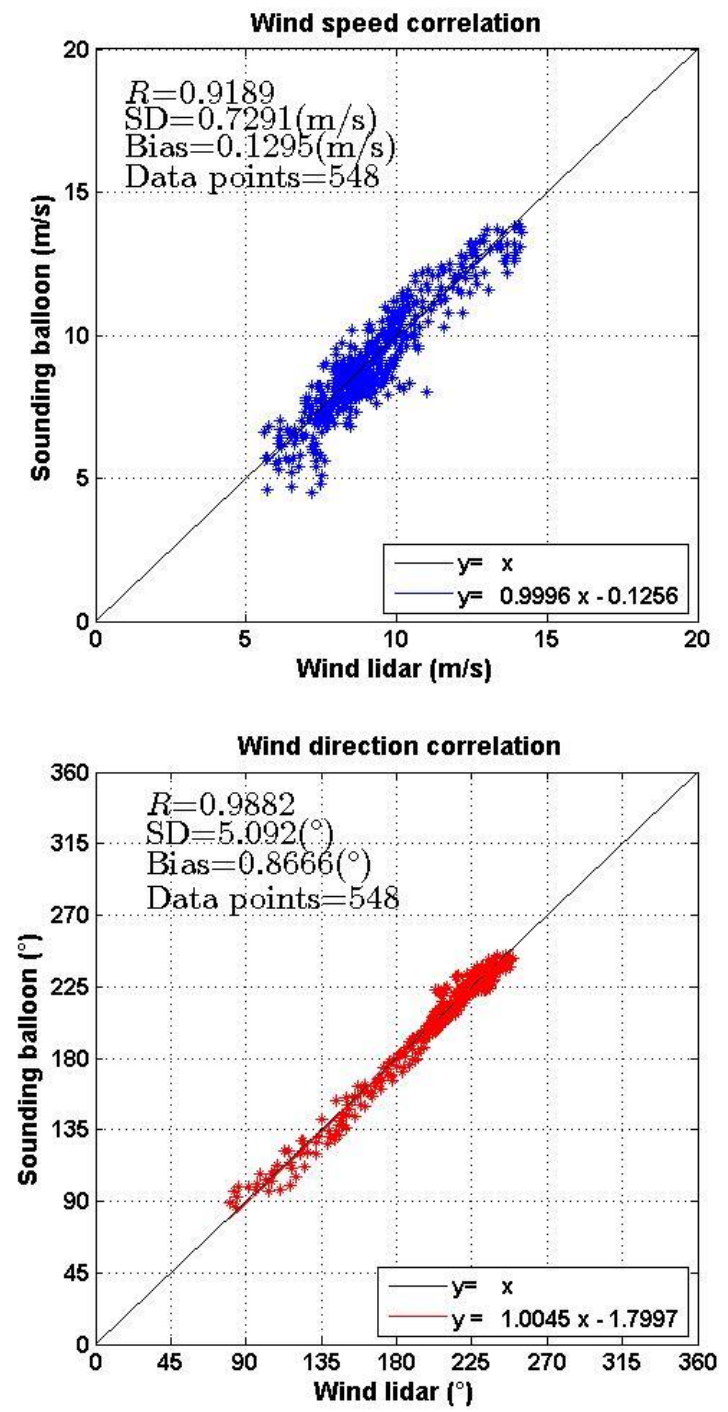

Figure 5: Linear correlation of wind speed and wind direction detected by CDL and sounding balloon.

The $1.5 \mu \mathrm{m}$ all-fiber pulsed CDL is used to measure wind profiles in the campaign experiments in Aug. 2018. The practical detection altitude is more than $4 \mathrm{~km}$ in hazy weather. The comparison with sounding balloon shows good agreement. This $1.5 \mu \mathrm{m}$ all-fiber pulsed CDL shows good performance in field experiments and potential application on ground-based or airborne platform in future.

\section{ACKNOWLEDGEMENTS}


This work was supported by the National Key R\&D Program of China under Grant No. 2017YFF0104600.

\section{REFERENCES}

[1] Liu, J., et al. All-Fiber Airborne Coherent Doppler Lidar to Measure Wind Profiles. in EPJ Web of Conferences. 2016. EDP Sciences.

[2] Inokuchi, H., H. Tanaka, and T. Ando, Development of an onboard doppler lidar for flight safety. Journal of aircraft, 2009. 46(4): p. 1411.

[3] Cariou, J. P., et al. Long range scanning pulsed Coherent Lidar for real time wind monitoring in the Planetary Boundary Layer. in Proceedings of 16th Conference on Coherent Laser Radar. 2011.

[4] Prasad, N.S., et al. Innovative fiber-laser architecture-based compact wind lidar. in SPIE OPTO. 2016. International Society for Optics and Photonics.

[5] Wu, S., et al., Wind turbine wake visualization and characteristics analysis by Doppler lidar. Optics express, 2016. 24(10): p. A762-A780. 